\title{
Biological compost stability influences odor molecules production measured by electronic nose during food-waste high-rate composting
}

\author{
Giuliana D'Imporzano ${ }^{a}$, Fernando Crivelli ${ }^{b}$, Fabrizio Adani ${ }^{a, *}$ \\ a Dipartimento di Produzione Vegetale, Via Celoria 2, 20133 Milano, Italy \\ b PCA Technologies, Via Molino 2, 21052 Busto Arsizio (VA), Italy
}

\section{A R T I C L E I N F O}

Article history:

Received 22 November 2007

Received in revised form

16 April 2008

Accepted 26 April 2008

Available online 6 June 2008

Keywords:

Biological stability

Composting

Dissolved organic matter

Dynamic respiration index

Electronic nose

Odor molecules

\begin{abstract}
A B S T R A C T
Composting is a technique that is used to convert organic waste into agriculturally useful products. Composting is an aerobic, solid-state biological process, which typically can be divided into two phases, a high-rate composting phase and a curing phase. High-rate composting plays an important role during the composting process, owing to the high microbial activity occurring during this phase. It requires an accurate plant design to prevent the formation of anaerobic conditions and odors. The formation of anaerobic conditions mainly depends on the rate of $\mathrm{O}_{2}$ consumption needed to degrade the substrate, i.e., the biological stability of the substrate.

In this study, we investigated the relationship between the biological activity, measured by the dynamic respiration index (DRI) and the odor molecules production, measured by an electronic nose (EN) during two food-waste high-rate composting processes. Although the $\mathrm{O}_{2}$ concentration in the biomass free air space (FAS) was kept optimal $\left(\mathrm{O}_{2}>140 \mathrm{ml} \mathrm{l}^{-1}, \mathrm{v} / \mathrm{v}\right)$ during composting, strong anaerobic conditions developed. This was indicated by the high levels of sulfur compounds, methane, and hydrogen in the outlet air stream. Both the high level of $\mathrm{O}_{2}$ consumption, needed to degrade the high-degradable water-soluble organic matter and the low water $\mathrm{O}_{2}$ solubility, caused by high temperature reached in this stage (up to $60{ }^{\circ} \mathrm{C}$ ), led to the anaerobic conditions observed in the biofilm-particle level. The application of the partial least square (PLS) analysis demonstrated a good regression between the DRI and the odor molecules produced that was detected by the EN $\left(R^{2}=0.991\right.$; $R_{C V}^{2}=0.990$ ), signifying the usefulness of the DRI as a parameter to estimate the potential production of odor molecules of the biomass.
\end{abstract}

(c) 2008 Elsevier B.V. All rights reserved.

\section{Introduction}

Generating compost from the organic fractions of municipal solid waste (MSW) and the use of this compost in agriculture combine low cost and environmentally safe waste discharge with the restoration of adequate organic levels in the agricultural field. This is particularly useful in industrialized agricultural systems lacking the input of organic matter.
The composting process is an aerobic, solid-state biological process consisting of a high-rate composting phase and a compost curing phase. The first phase is characterized by an intense microbial activity leading to the decomposition of the most biodegradable material, until the biological stability is reached. The second phase is characterized by a slow degradation process and by the transformation of the more recalcitrant molecules into humic substances (Adani et al., 1997).

\footnotetext{
* Corresponding author. Tel.: +3902 50316545; fax: +39 0250316521.

E-mail address: fabrizio.adani@unimi.it (F. Adani).
} 
Because of the intense microbial activity that occurs when food wastes are composted, the high-rate phase is considered predominantly important. To achieve optimal composting conditions, the composting plants need to be designed to achieve correct air management $\left(\mathrm{O}_{2}\right.$ supplier), optimal water content, and bulk density. All these factors are fundamental for the composting process to proceed rapidly to the aerobic degradation of the more easily degradable organic matter, and to prevent the formation and volatilization of organic molecules, i.e., volatile organic compounds (VOCs) (Smet et al., 1999, Komilis et al., 2004; Romain et al., 2005). The latter is particularly relevant as VOCs can cause irritations and health problems to the neighboring residential areas, owing to their malodorous and hazardous properties (Komilis et al., 2004; Herr et al., 2003).

If the composting process is unable to proceed properly (i.e., biomass is too wet or biomass bulk density is too high or air supply is insufficient), then the $\mathrm{O}_{2}$ molecules fail to diffuse into the biomass, creating areas where the malodorous molecules are produced as a consequence of the anaerobic conditions (Clemens and Cuhls, 2003; Schlegelmilch et al., 2005).

VOCs produced during composting can have xenobiotic origins (e.g., aromatic hydrocarbons), owing to the presence of household hazardous wastes in the composted mixtures (e.g., unsorted MSW) (Komilis et al., 2004; Romain et al., 2005). In this case, the VOCs volatilize primarily during the first biological composting stages (Perucci et al., 2005). In contrast, during the composting of selected organic fractions (e.g., food wastes), VOCs are mostly of a biogenic origin and are produced predominantly during the high-rate composting phase (Romain et al., 2005). In this case, sulfides, followed by acid/ esters, ketones, alcohols, and terpenes, have been reported to be the typical VOCs produced during composting (Komilis et al., 2004; Mao et al., 2006).

Anaerobic conditions leading to the production of odors occur if the $\mathrm{O}_{2}$ concentration in the inlet airflow is not optimal. Earlier studies (Suler and Finstein, 1977; Hamelers, 2001) revealed that no significant variation occurred in the biomass $\mathrm{O}_{2}$ consumption and the composting proceeded properly under aerobic conditions, when the $\mathrm{O}_{2}$ level of $100 \mathrm{ml} \mathrm{l}^{-1}$ (v/ v) or more was maintained in the biomass free air space (FAS). Nevertheless, even with active ventilation and optimal $\mathrm{O}_{2}$ concentration in the FAS, high amounts of odors can still be produced, indicating that diffusion is required to transport $\mathrm{O}_{2}$ into the biomass particle/biofilm interface, even though ventilation supplies $\mathrm{O}_{2}$ into the biomass FAS (Miller, 1993).

Composting can be considered as a solid-state biological process, in which composting reactions occur at the solid particle level. A single solid particle is formed by an anaerobic core, surrounded by a wet biofilm (Hamelers, 2001). It is in the anaerobic core that the hydrolysis of the insoluble substrate takes place; while in the biofilm, the soluble substrates (dissolved organic matter, DOM), originating from the anaerobic zone, are oxidized consuming $\mathrm{O}_{2}$ and producing $\mathrm{CO}_{2}$, $\mathrm{NH}_{3}, \mathrm{H}_{2} \mathrm{O}$, and heat (Hamelers, 2001). The concentration gradient, necessary to induce $\mathrm{O}_{2}$ diffusion from the gaswaste particle interface to the biofilm is created by the oxygen uptake rate (OUR) of aerobic biomass, to degrade the DOM (Hamelers, 2001). Further in-depth studies revealed that the biofilm age, thickness, density, porosity, and tortuosity are also important for mass transfer phenomena (Hibiya et al., 2004). If the OUR does not exceed the $\mathrm{O}_{2}$ diffusion rate into the biofilm, aerobic conditions are ensured, whereas when the OUR exceeds the $\mathrm{O}_{2}$ diffusion rate into the biofilm, anaerobic conditions occur and the odorous organic molecules are produced. Therefore, it could be assumed that at the particle level, in the presence of optimal $\mathrm{O}_{2}$ concentration at the gasparticle interface, the odor production depends on the OUR, which is a function of the quantity (concentration) and the quality (degradability degree) of the DOM present in the biofilm.

The $\mathrm{O}_{2}$ uptake rate needed to degrade a substrate is directly related to the degradability of the substrate (Adani et al., 2004). The degradability of the substrate can be measured by using lab tests and data reported on a recognized scale of values, i.e., respiration indexes (Adani et al., 2004). This measure represents the biological stability of a biomass (Adani et al., 2004), and therefore, the production of odors and the biological stability of a biomass are related issues.

This work was designed to evaluate the relationship between the biological stability of a substrate and the odors measured by an electronic nose (EN), produced during a labscale composting process, performed under optimal aeration condition.

\section{Materials and methods}

Two high-rate composting processes (Trials C1 and C2) were conducted using an adiabatic reactor with a 201 capacity by using approximately $9 \mathrm{~kg}$ of fresh biomass (Adani et al., 2001).

Composting processes were continuously monitored for both the $\mathrm{O}_{2}$ concentration, measured in the outlet air stream by a Clark-type temperature compensation electrode (Instrumentation Laboratory S.p.A., Italy) and the temperature, measured in the middle of the biomass using a heatresistant temperature electrode (Pt 100 Tersid Came, Italy). The $\mathrm{O}_{2}$ concentration in the outlet air stream was kept at a concentration of $140 \mathrm{ml} \mathrm{l}^{-1}(\mathrm{v} / \mathrm{v})$ by feedback control of the airflow rate. The composted mixtures consisted of two different organic fractions of MSW and lignocellulosic material (2:1 ratio w/w; moisture content of $550 \mathrm{~g} \mathrm{~kg}^{-1} \mathrm{ww}$ (wet weight); and $565 \mathrm{~g} \mathrm{~kg}^{-1} \mathrm{ww}$; volatile solids (VS) content of $540 \mathrm{~g} \mathrm{~kg}^{-1} \mathrm{dm}$ (dry matter) and $510 \mathrm{~g} \mathrm{~kg}^{-1} \mathrm{dm}$, respectively, for Trials $\mathrm{C} 1$ and $\mathrm{C} 2$ ), directly sampled from the full-scale plants. Biomass bulk density, measured directly in the reactor was $0.45 \mathrm{mg} \mathrm{m}^{-3}$ and contained a FAS of $35 \%(\mathrm{v} / \mathrm{v})$ for both the biomasses. The high FAS ensured optimal $\mathrm{O}_{2}$ distribution within the biomass (Madejon et al., 2002; Berthe et al., 2007).

Each trial lasted until the $\mathrm{O}_{2}$ uptake rate, measured as the dynamic respiration index (DRI), was below $1000 \mathrm{mg} \mathrm{O}_{2} \mathrm{O}_{2} \mathrm{~kg}$ $\mathrm{VS}^{-1} \mathrm{~h}^{-1}$ (approximately 11 days) (Adani et al., 2004).

The DRI was determined directly during the composting trails, by measuring the difference in the $\mathrm{O}_{2}$ concentration (ml $\mathrm{l}^{-1}$ ) between the inlet and the outlet air flow, the air having passed through the biomass, as well as by using the knowledge of the absolute content of VS (kg) in the biomass, the flow rate $\left(\mathrm{h} \mathrm{h}^{-1}\right)$, and the time (h) during which $\mathrm{O}_{2}$ consumption was 

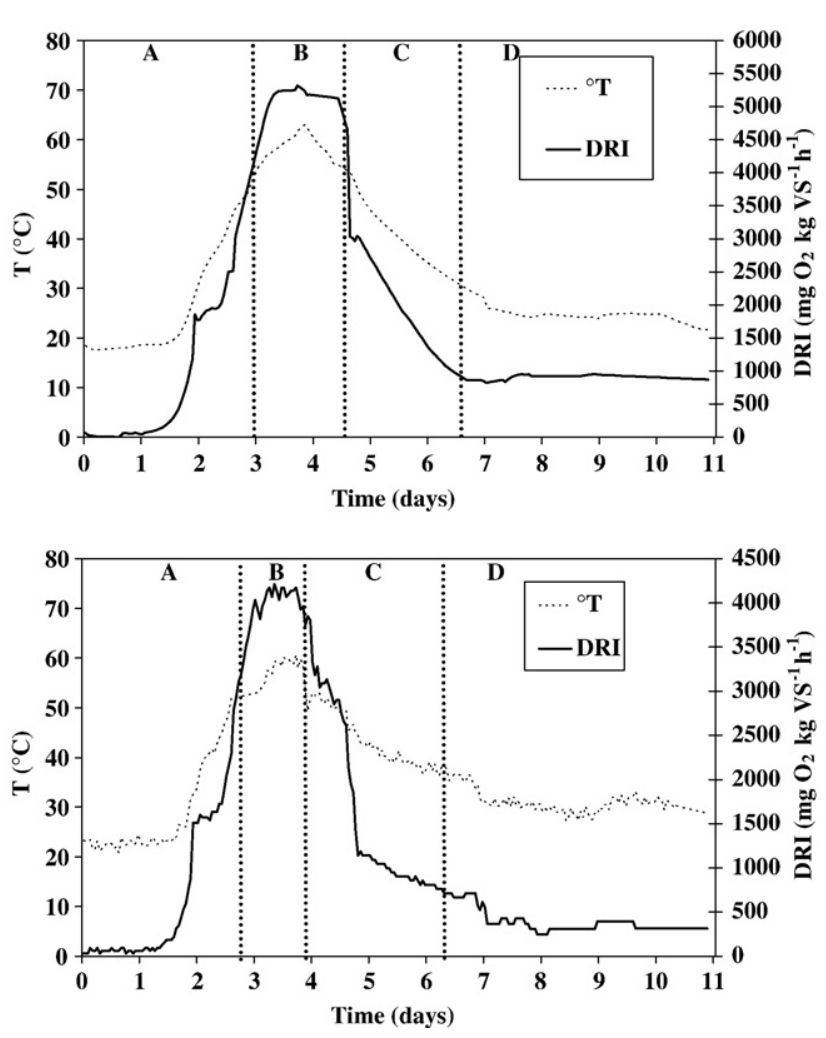

Fig. 1-Processes parameters behavior during high-rate composting processes. Up Trial C1; bottom Trial C2. A, B, C and D: phases used to describe composting processes (compost samples were took at time $0 \mathrm{~h}, 84 \mathrm{~h}, 108 \mathrm{~h}, 156 \mathrm{~h}, 192 \mathrm{~h}$ and $216 \mathrm{~h}$; odor molecules were sampled at time $36 \mathrm{~h}, 84 \mathrm{~h}$, $192 \mathrm{~h}$ and $216 \mathrm{~h})$.

measured, as described previously by Adani et al. (2004). The DRI was calculated as:

$$
\begin{aligned}
\operatorname{DRI}\left(\mathrm{mg} \mathrm{O}_{2} \mathrm{~kg}^{-1} \mathrm{VS}^{-1} \mathrm{~h}^{-1}\right)= & \mathrm{Q} \times \theta \times \Delta \mathrm{O}_{2} \times \mathrm{Vg}^{-1} \times 31.98 \\
& \times \mathrm{VS}^{-1} \times \theta^{-1}
\end{aligned}
$$

where $Q\left(1 \mathrm{~h}^{-1}\right)$ represents the airflow, $\theta$ is the acquisition time $(1 \mathrm{~h}), \Delta \mathrm{O}_{2}\left(\mathrm{ml} \mathrm{l}^{-1}\right)$ is the difference in $\mathrm{O}_{2}$ concentration in the inlet and outlet air flow of the reactor, $\mathrm{Vg}\left(1 \mathrm{~mol}^{-1}\right)$ is the volume occupied by $1 \mathrm{M}$ of gas at inlet air temperature, $31.98\left(\mathrm{~g} \mathrm{~mol}^{-1}\right)$ is the molecular weight of $\mathrm{O}_{2}$, and VS $(\mathrm{kg})$ is the total volatile solids.

During high-rate composting of each trial, six representative samples (Samples 1-6) were collected from the biomass (The U. S. Composting Council, 1997) at different composting phases (A, B, C, and D) (D'Imporzano and Adani, 2007) (Fig. 1): at the beginning of the trial (Sample 1) (Phase A); when the maximum DRI was reached (Sample 2) (Phase B); when the OUR started to decrease (Sample 3) (Phase C); when the OUR decreased (Sample 4) (Phase $\mathrm{C}$ ); after biological stability was achieved, i.e., OUR $<1000 \mathrm{mg} \mathrm{O}_{2} \mathrm{O}_{2} \mathrm{~kg} \mathrm{VS}^{-1} \mathrm{~h}^{-1}$ (Sample 5) (Phase D); and at the end of the trial (Sample 6) (Phase D). The sampling progressed by the complete mixing and turning of the biomass, and successive sampling of the biomass-cores that were mixed to give final samples of approximately $500 \mathrm{~g}$. Water was added when required. These procedures ensured both the optimal moisture and FAS contents for all the processes.
Each sample was dried at $60^{\circ} \mathrm{C}$ under vacuum, grinded up to $0.5 \mathrm{~mm}$ by blade-mill, and stored for subsequent analysis. Each sample was characterized for total organic carbon (TOC) contents (The U.S. Composting Council, 1997). Successively, the DOM was determined twice, as reported in the earlier studies (D'Imporzano and Adani, 2007). Particularly, $5 \mathrm{~g}$ of dried material was extracted with water (1:20, solid:liquid ratio, w/w) using a Dubnoff bath at $60 \mathrm{rpm}$ for $30 \mathrm{~min}$ at $40^{\circ} \mathrm{C}$. The extraction parameters were previously set up (data not published) to obtain the highest DOM yield, avoiding hydrolysis processes. The suspension obtained was then centrifuged for $15 \mathrm{~min}$ at $6500 \mathrm{rpm}$ and successively filtered by fast cellulose filter (Whatman paper filter N.4) and then by $0.45 \mu \mathrm{m}$ millipore membrane (Advantec MFS, Pleasanton, CA). The solutions obtained represented the DOM. The DOMs extracted were quantified by organic carbon determination (ISO, 2002).

Compost and DOM samples, obtained at different composting times, underwent a degradation test performed under nolimiting conditions, by measuring the OUR under liquid condition (OURL) for the organic carbon degradation (Cox and Deshusses, 1998). All the compost samples were tested. On the other hand, as OURL test on water extract was laborious, only three key DOM samples (Samples 1, 3, and 6) were tested. The selection took into consideration the DOM content of the starting biomasses (Sample 1) that did not show appreciable decrease in their content, till the microbial activity started to decrease (Sample 3; Phase C), becoming very low at the end of the process (Sample 6) (Phase D) (Hamelers, 2001; D'Imporzano and Adani, 2007).

The test was performed following the method reported by D'Imporzano and Adani (2007). In brief, OURL was measured for $20 \mathrm{~h}\left(\mathrm{OURL}_{20}\right)$ under liquid conditions using a solid:liquid ratio of $1: 100(\mathrm{w} / \mathrm{w})$ at $37 \pm 1{ }^{\circ} \mathrm{C}$. During the test, standard conditions were maintained to ensure optimum microbial activity and reaction rates. In particular, for the purpose of ensuring the occurrence of no growth limiting conditions, with respect to $\mathrm{pH}$ and element nutrition (Lasaridi and Stentiford, 1998), $5 \mathrm{~g}$ of dry matter (or aqueous extracts obtained from $5 \mathrm{~g}$ of dry matter) was set in a flask to which the following were added: $500 \mathrm{ml}$ of deionized water, $12 \mathrm{ml}$ of phosphate buffer solution, and $5 \mathrm{ml}$ of nutritive solution $\left(\mathrm{CaCl}_{2}, \mathrm{FeCl}_{3}\right.$, and $\left.\mathrm{MgSO}_{4}\right)$. No nitrogen was added to the slurry that was kept under agitation by a magnetic stirrer, performing intermittent aeration every $15 \mathrm{~min}$. The OURL was detected, by measuring the slope of the decrease of the $\mathrm{O}_{2}$ concentration in the slurry during the absence of aeration (Lasaridi and Stentiford, 1998). The degree of biodegradability was reported as the cumulative $\mathrm{O}_{2}$ consumption during the $20 \mathrm{~h}$ test period $\left(\mathrm{mg} \mathrm{O}_{2} \mathrm{~g}^{-1} \mathrm{C}^{-1} 20 \mathrm{~h}^{-1}\right)$.

During the processes, odor molecules analyses were performed by an electronic nose (EN) (Airsense - model PEN3, Airsense Analytics, Schwerin, Germany), equipped with 10 different thermo-regulated $\left(150-500^{\circ} \mathrm{C}\right)$ sensors $(\mathrm{S})$ made of metal oxide semiconductors (MOS). The sensors, positioned into a measurement chamber (1.8 $\mathrm{ml}$ of volume), are sensitive to different classes of chemical compounds: S1-aromatic compounds; S2-polar compounds and $\mathrm{NO}_{x}$; S3-aromatic compounds, ketones, and aldehydes; $\mathrm{S} 4-\mathrm{H}_{2}$; $\mathrm{S} 5-$ low polarity aromatic and alkane compounds; S6-methane compounds; S7-sulfur compounds and terpenes, which strongly odorize; 
S8 - broad alcohols, ketones, and partially aromatic compounds; S9 - sulfur-containing and aromatic compounds; S10 - methane at high concentration. During the measurements, the instrument was directly connected to the reactor and the air sample (from the outlet airflow) was sucked through the sensor array.

Before the measurement started, the system (tube and sensor array chamber) was cleaned by a cycle of $300 \mathrm{~s}$, using filtered air (zero-air: air filtered on active carbon), to ensure the absence of the residual odor molecules and to report sensors to the baseline, in the measurement chamber.

The working parameters adopted were as follows: (i) measuring time of $100 \mathrm{~s}$ (sample sucked in sensor array), during which sensor analysis was performed every second (for a total of 100 measures), which allowed sensors stabilization. The last 20 measures were used to create the sensor patterns. Taking into consideration an airflow rate of $400 \mathrm{ml} \mathrm{min}{ }^{-1}$, the total volume sucked was $666 \mathrm{ml}$, (ii) flush time of $300 \mathrm{~s}$ (after the measuring time, the system was cleaned with zero-air), (iii) a cycle number of 4, i.e., the procedures (i) and (ii) were repeated for four times for each sampling that were randomly performed, to verify the signal stability and to get a sufficient number of data that allowed considering all sample variations.

The validation of the memorized odor patterns, coming from the four measurement cycles, was made by using the technique of cross-validation-leave one out, by using a linear discriminant analysis (LDA).

The large amount of information obtained by the EN required the reduction of the dimensionality (generally twodimensional). As a consequence, odor results were elaborated by a multivariate analysis (Göbel, 1998).

In this work, principal component analysis (PCA) was used to compare odors qualitatively and partial least squares (PLS) regression was used to detect regression between the DRI and odors.

The multivariate analyses were carried out by ad hoc software (Win Muster vers. 1.6, by Airsense Analytics, Germany).

Odor molecules were detected during the processes at different decomposition stages: starting (Time $36 \mathrm{~h}$ ) (Phase A) (Fig. 1), highest biological activity (Time 84 h) (Phase B) (Fig. 1), and at the end of composting (Time 216 h) (Phase D) (Fig. 1). Odors detected were associated to the corresponding DRI measured just prior to sampling. Following the odor detection, biomass samples were taken as previously described (Samples $1,3,5$, and 6).

\section{Results}

High-rate composting processes displayed typical trends as represented by the process parameters, i.e., DRI and temperature (T) (Fig. 1) (Perucci et al., 2005). The DRI trend described a typical microbial growth kinetic on the available non-limiting substrate, which typically characterizes the first step of a composting process (high-rate stage) (D'Imporzano and Adani, 2007). Both processes exhibited a rapid increase in the $\mathrm{O}_{2}$ uptake, mainly because of the degradation of the soluble fractions (DOM) contained in the biomass (Table 1) (SaidPullicino et al., 2007; D'Imporzano and Adani, 2007). Microbial activity remained high, until the DOM content was elevated (Phases A and B) (Fig. 1, Table 1). Both the soluble carbon content and the microbial activity decreased simultaneously (Phase C) (Fig. 1) and was dependent on the rate of biomass hydrolysis (Phases D) (Fig. 1, Table 1) (D'Imporzano and Adani, 2007). After 11 days of composting, the DRI values for both processes were much lower than $1000 \mathrm{mg} \mathrm{O}_{2} \mathrm{O}_{2} \mathrm{~kg} \mathrm{VS}^{-1} \mathrm{~h}^{-1}$, indicated in the past as the limit of biological stability (Adani et al., 2004).

During the processes, chemical parameters changed in response to the biological activity, i.e., the $\mathrm{O}_{2}$ uptake rate. Both the TOC and the DOM decreased in both the trials (Table 1). Decreases in DOM concentrations were sharper than the TOC ones, owing to their different biological availability. The TOC and DOM degradation for both trials were well described by the first-order degradation kinetics. The reaction constant rates $(k)$ for TOC were half of $k$-DOM (Table 1$)$, confirming the high DOM degradability.

Biodegradability tests performed on compost and DOM samples provided information concerning both their degradability over the time and the contribution of DOM to the total compost degradability (Table 2). Composts showed a decrease in their degradability coefficients (Compost-OURLs) at the end

Table 1 - Total organic carbon (TOC) and dissolved organic matter (DOM) contents determined for compost samples and water extracts from compost samples during composting trials

\begin{tabular}{|c|c|c|c|c|c|}
\hline \multirow[t]{2}{*}{ Sample } & \multirow{2}{*}{$\begin{array}{c}\text { Time } \\
\text { (h) }\end{array}$} & \multicolumn{2}{|c|}{ Trial C1 } & \multicolumn{2}{|c|}{ Trial C2 } \\
\hline & & TOC $\left(g C \mathrm{~kg} \mathrm{dm}{ }^{-1}\right)^{\mathrm{a}}$ & $\operatorname{DOM}\left(\mathrm{g} \mathrm{C} \mathrm{kg} \mathrm{dm}{ }^{-1}\right)$ & TOC (g C kg dm ${ }^{-1}$ ) & $\mathrm{DOM}\left(\mathrm{g} \mathrm{C} \mathrm{kg} \mathrm{dm}{ }^{-1}\right)$ \\
\hline $1(\mathrm{~A})^{\mathrm{b}}$ & 0 & $437.7 \pm 19.0 b^{c}$ & $33.1 \pm 0.9 f$ & $406.7 \pm 7.4 \mathrm{~d}$ & $25.1 \pm 0.1 \mathrm{c}$ \\
\hline 2 (B) & 84 & $402.8 \pm 7.5 \mathrm{ab}$ & $26.4 \pm 0.3 e$ & $399.8 \pm 8.3 c$ & $24.2 \pm 0.1 \mathrm{c}$ \\
\hline $3(\mathrm{C})$ & 108 & $389.30 \pm 5.6 a$ & $19.0 \pm 0.0 \mathrm{~d}$ & $408.8 \pm 4.6 \mathrm{~cd}$ & $19.9 \pm 0.6 b$ \\
\hline $4(C)$ & 156 & $396.1 \pm 12.6 a b$ & $13.3 \pm 0.3 c$ & $387.5 \pm 10.2 b$ & $15.1 \pm 0.2 \mathrm{a}$ \\
\hline 5 (D) & 192 & $383.6 \pm 0.9 a$ & $8.5 \pm 0.8 \mathrm{a}$ & $382.4 \pm 2.6 b$ & $14.7 \pm 0.6 \mathrm{a}$ \\
\hline 6 (D) & 216 & $377.7 \pm 0.5 a$ & $12.0 \pm 0.5 b$ & $355.9 \pm 10.6 a$ & $15.0 \pm 0.7 a$ \\
\hline$k\left(\mathrm{~d}^{-1}\right)^{\mathrm{d}}$ & & 0.071 & 0.16 & 0.072 & 0.11 \\
\hline \multicolumn{6}{|c|}{$\begin{array}{l}\text { a All data reported as g of carbon for kg of compost dry matter }(\mathrm{dm}) \text {. } \\
\text { b Composting phase, see Fig. } 1 \text {. } \\
\text { c Means followed in the same column by the same letter are not statistically different }(\mathrm{P}<0.05) \text { according to Tukey test. } \\
\text { d Degradation constant rates calculated for compost and DOM. }\end{array}$} \\
\hline
\end{tabular}


Table 2 - Biodegradability tests performed on compost and dissolved organic matter extracted from compost samples

\begin{tabular}{|c|c|c|c|c|c|}
\hline \multirow[t]{3}{*}{ Sample } & \multirow[t]{3}{*}{ Time (h) } & \multicolumn{2}{|c|}{ Trial C1 } & \multicolumn{2}{|c|}{ Trial C2 } \\
\hline & & Compost-OURL & DOM-OURL & Compost-OURL & DOM-OURL \\
\hline & & \multicolumn{4}{|c|}{$\left(\mathrm{mg} \mathrm{O}_{2} \mathrm{gC}^{-1} 20 \mathrm{~h}^{-1}\right)$} \\
\hline $1(\mathrm{~A})^{\mathrm{a}}$ & 0 & $114.8 \pm 17.4 c^{b}$ & $678 \pm 3 a$ & $91.3 \pm 7.7 c$ & $1001 \pm 87 c$ \\
\hline 2 (B) & 84 & $131.6 \pm 10 d$ & n.d. ${ }^{c}$ & $98.9 \pm 6.5 c$ & n.d. \\
\hline $3(\mathrm{C})$ & 108 & $102.4 \pm 10.8 b$ & $625 \pm 90 a$ & $100.8 \pm 0.8 c$ & $433 \pm 41 a$ \\
\hline $4(\mathrm{C})$ & 156 & $83.8 \pm 10 a b$ & n.d. & $77.5 \pm 10.4 b$ & n.d. \\
\hline 5 (D) & 192 & $69.2 \pm 7.3 a$ & n.d. & $95.1 \pm 7.3 c$ & n.d. \\
\hline 6 (D) & 216 & $74.9 \pm 3.7 a$ & $932 \pm 69 b$ & $51.4 \pm 12.3 \mathrm{a}$ & $700 \pm 5 b$ \\
\hline
\end{tabular}

of the processes (Samples 5 and 6) (Phases D) (Fig. 1). This was due to the depletion of the more easily degradable organic fraction in the compost (i.e., DOM plus easily hydrolyzable organic fraction) (Table 1) (Hamelers, 2001; Adani et al., 2004). The DOM samples (Table 2) always displayed higher OURL values than the composts, which were consistent with the kinetic values (Table 1) (Hamelers, 2001). The DOM degradability degree showed a different trend in the two trials: an increase in the first (Trial C1) and a decrease in the second (Trial C2), although the DOM-OURLs were not that different and remained high during all processes for both the trials (DOM-OURL $=728 \pm$ $\left.208 \mathrm{mg} \mathrm{O}_{2} \mathrm{gC}^{-1} 20 \mathrm{~h}^{-1}\right)($ mean \pm s.d., $n=6)$.

Organic molecules in the exhaust air stream measured during composting using the EN were not the same for the different composting stages, but were similar for the two processes studied (Fig. 2). More interesting was the finding that similar odor molecule patterns corresponded to composting phases characterized by similar DRI, i.e., the biological stability affected the odor molecules production (Fig. 2). For the starting samples (Phase A in Fig. 1), the EN mostly registered the presence of aromatic and sulfur compounds. Signals were not as strong as the air sampled during the highest microbial activity (highest DRI) (Phase B), which was characterized mainly by the presence of sulfur compounds, methane, and hydrogen, all indicative of strong anaerobic conditions (Homos and Fisher, 1992; Romain et al., 2005). The final stages of the composting processes (Phase D) presented higher DRI than the starting ones, which were characterized by their low sensor signals. Although the starting phases had a high substrate availability, the low DRI
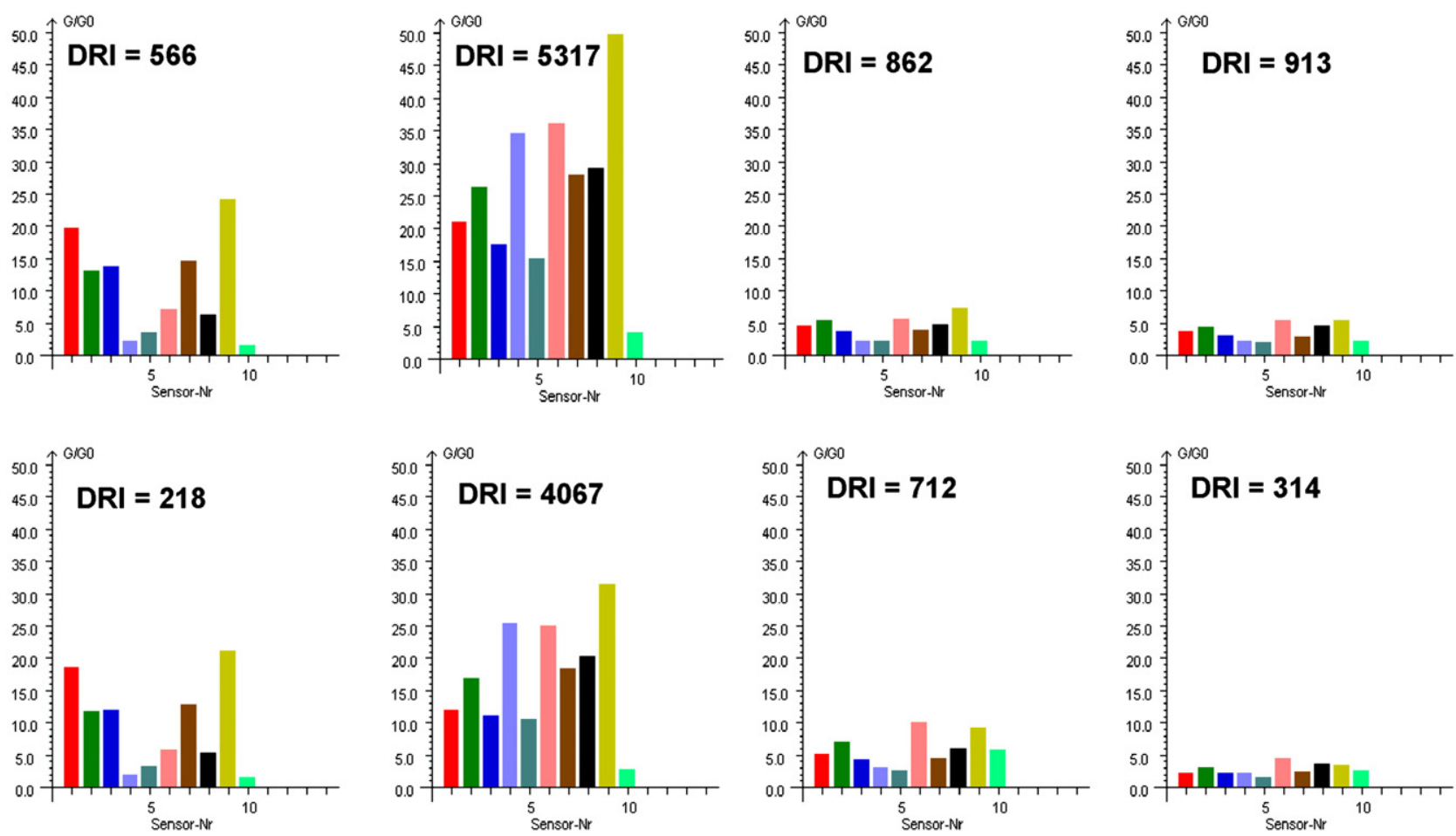

Fig. 2-PEN-Airsense electronic nose signals registered during the two high-rate composting processes. $y$ axis relative sensor signals; $x$ axis sensor number. DRI values ( $\left.\mathrm{mg} \mathrm{O}_{2} \mathrm{~kg} \mathrm{VS}^{-1} \mathrm{~h}^{-1}\right)$ measured during odor sampling (up: Trial C1; bottom: Trial C2). 


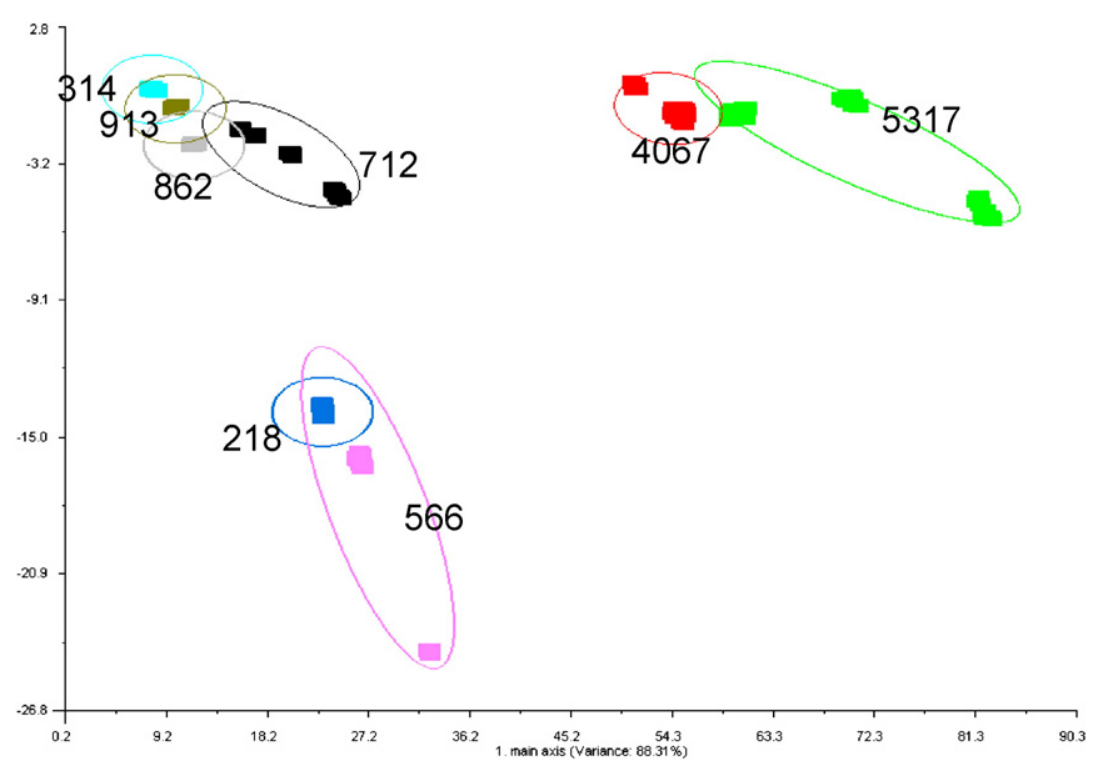

Fig. 3-Bi-dimensional PCA plot for odors measured by PEN-Airsense. $y$ axis PC2, $x$ axis PC1. Each odor is associated to the DRI measured during odor sampling.

measured for these phases was due to the low presence of microbial populations during this phase (microbial growth phase).

Successive chemometric analyses allowed for a better investigation of this relationship. First, a loading plot was obtained to determine which sensors and relative compounds fitted well with DRI. These plots show that the compound classes (sensor) that best-described the DRI were S2, S4, S5, S6, S7, S8, and S9. The successive application of PCA analyses using the best-fitting sensors provided two principal components. The results were well summarized by the bi-dimensional PCA plot (PC2 us. PC1) (Fig. 3). As PC1 accounted for $88.3 \%$ of the total system variance, the $x$-axis of the plot was effective in distinguishing each odor pattern characterized by its DRI value. Fig. 3 indicates that the odor molecule patterns for samples taken when the biological activity was low were similar (low DRI) (Fig. 1), i.e., starting and ending of the processes, but were different from the odor patterns detected when the processes were characterized by high biological activity (highest DRI) (Fig. 1).

\section{Discussion}

High-rate composting processes progressed by the degradation of the easily degradable organic fractions. During this phase, the pre-existing soluble carbon and the one coming from the hydrolysis of the easily degradable insoluble substrate provided the main source of organic nutrients to the microorganisms (Said-Pullicino and Gigliotti, 2007).

All these events occurred in the particle-biofilm, a thin layer on the compost particles, composed of solid substrate and microorganism, water, and gases (Hamelers, 2001), in which both hydrolysis of the insoluble substrates, oxidation of the soluble carbon, and gas exchange occurs (Hamelers, 2001). Results suggested that the strong odor production occurred when the maximum biological activity took place (highest DRI) (Phase $\mathrm{B}$ ). As the $\mathrm{O}_{2}$ concentration in the biomass FAS was kept constant and optimal $\left(\mathrm{O}_{2}>140 \mathrm{ml} \mathrm{l}^{-1} ; \mathrm{v} / \mathrm{v}\right)$ throughout the composting processes, the DOM content and OURs were the main parameters that could affect the $\mathrm{O}_{2}$ concentration in the biofilm (Hamelers, 2001). The presence of DOM in the biofilm was dependent on its initial concentration in the biomass, by the hydrolysis rate of the insoluble substrate, and by the substrate diffusion from solid substrate to the biofilm; the latter could be assumed to be constant during the process (Hamelers, 2001). Again, the $\mathrm{O}_{2}$ concentration in the biofilm depended on the OUR and temperature.

When the $\mathrm{O}_{2}$ uptake rate for compost samples was measured under optimal conditions (Compost-OURL) (Table 2 ), it correlated well with the DOM content of compost ( $r=0.75$; $P<0.05 ; n=12)$, suggesting that the DOM-compost content was primarily responsible for compost $\mathrm{O}_{2}$ consumption (SaidPullicino and Gigliotti, 2007). High DOM content and high DOM-OURL were typical for samples taken during Phase B of the composting processes that presented the highest DRIs. Phase $\mathrm{B}$ was also characterized by highest temperatures ( $\mathrm{T}$ approximately $60{ }^{\circ} \mathrm{C}$ ) (Fig. 1). We calculated that $\mathrm{O}_{2}$ water solubility at $60{ }^{\circ} \mathrm{C}$ was $49 \%$ lower than that calculated at $20^{\circ} \mathrm{C}$ (Phase A), as solubility decreases with increasing temperature (American Public Health Association, 1965).

The above-discussed conditions lead to the $\mathrm{O}_{2}$ depletion during Phase $\mathrm{B}$, which is responsible for the high level of odor production during this stage. Therefore, with respect to the early composting processes, the low microbial population limited the degradation processes (Phase A), even though the substrate was highly obtainable (high DOM content) and therefore the $\mathrm{O}_{2}$ consumption in the biofilm was low, maintaining aerobic conditions and limiting odor production. In contrast, during Phase $\mathrm{B}$, the substrate still continues to be a non-limiting factor, but $\mathrm{O}_{2}$ becomes limiting, because of its rapid consumption due to both the high microbial activity 
(highest DRI) and low $\mathrm{O}_{2}$ solubility, as a result of higher temperature. The successive decrease of the available substrate and temperature during the latter phases (Phases $\mathrm{C}$ and D) reduced the $\mathrm{O}_{2}$ demand and so any limitation for the aerobic degradation process. The relationship between microbial activity (DRI) and odor production was confirmed by the application of the PLS analysis (Abdi, 2003) that displayed an optimal linear regression between these two measurements $\left(R^{2}=0.991 ; R^{2}\right.$ CV $\left.=0.991, P<0.01\right)$.

In conclusion, high odor production coincides with both high microbial activity and high compost temperature, causing $\mathrm{O}_{2}$ depletion in the biofilm. Keeping high partial pressure of $\mathrm{O}_{2}$ in the particle-biofilm can result in the reduction of odor production. This can be achieved by increasing the $\mathrm{O}_{2}$ partial pressure in the inlet air-flux by using, for example, enriched$\mathrm{O}_{2}$ air. Further investigations are required to study the reduction of odors by using $\mathrm{O}_{2}$-enriched air.

The establishment of good relationship between odor production and biological stability (DRI) will result in important practical applications in waste management and related environmental management practices, as DRI detection can represent a measurement of the potential odors impact on a biomass, stored in open air. By now, no rules consider the measurement of the biological stability as a surrogate of the odor analysis, the former being less expensive. Next step of our research will be to focus on the existence of regression among odors measured by olfactometric analysis (odor units), odors detected by EN, and biological stability. If regression is found, the DRI could be used instead of more laborious and expensive olfactometric analyses to predict the impact of odors in biomasses.

\section{R E F E R E N C E S}

Abdi H. Partial least squares (PLS) regression. In: Bryman LM, Futing A, editors. Encyclopedia of social science research methods. Thousand Oaks: CA; 2003. p. 1-7.

Adani F, Confalonieri R, Tambone F. Dynamic respiration index as descriptor of the biological stability of organic wastes. J Environ Qual 2004;33:1866-76.

Adani F, Genevini PL, Gasperi F, Zorzi G. Organic matter evolution index (OMEI) as a measure of composting efficiency. Compost Sci Utiliz 1997;5:5-62.

Adani F, Lozzi P, Genevini PL. Determination of biological stability by oxygen uptake on municipal solid waste and derived products. Compost Sci Util 2001;9:163-78.

American Public Health Association. Standard methods for the examination of water and wastewater. 12th ed. New York: American Public Health Association; 1965. p. 408-10.

Berthe L, Druilhe C, Massiani C, Tremier A, de Guardia A. Coupling a respirometer and a pycnometer, to study the biodegradability of solid organic wastes during composting. Biosyst. Stud. 2007;97:75-88.
Clemens J, Cuhls C. Greenhouse gas emission from mechanical and biological waste treatment of municipal solid waste. Environ Technol 2003;24:745-54.

Cox HHJ, Deshusses MA. Biological waste air treatment in biotrickling filters. Curr Opin Biotechnol 1998;9:256-62.

D'Imporzano G, Adani F. The contribution of water soluble and water insoluble organic fractions to oxygen uptake rate during high rate composting. Biodegradation 2007;18:103-13.

Göbel W. Chemical imaging: I. Concepts and vision for electronics and bioelectronics noses. Sens Actuators, B 1998;52:125-42.

Hamelers HVM. A mathematical model for composting kinetics. Ph. D. Thesis, University of Wageningen, The Netherlands, 2001.

Herr CEW, zur Nieden A, Bödeker RH, Gieler U, Eikann TF. Ranking and frequency of somatic symptoms near composting sites with odor annoyance. Int J Hyg Environ Health 2003;206:61-4.

Hibiya K, Satoshi JN, Tsuneda S, Hirata A. Simple prediction of oxygen penetration depth in biofilms for wastewater treatment. Biochem Eng J 2004;19:61-8.

Homos WJ, Fisher K. A composting plants as an odours source, compost as and odour killer. Acta Horticulturae 1992;302:37-44.

ISO 16072. Soil quality: laboratory methods for determination of microbial soil respiration; 2002.

Komilis DP, Ham RK, Park JK. Emission of volatile organic compounds during composting of municipal solid wastes. Water Res 2004;38:1707-14.

Lasaridi KE, Stentiford EI. A simple respirometric technique for assessing compost stability. Water Res 1998;32:3717-23.

Madejon E, Diaz MJ, Lopez R, Cabrena F. New approaches to establish optimum moisture content for compostable materials. Biores Technol 2002;85:73-8.

Mao I-F, Tsai C-J, Shen S-H, Lin T-F, Chen W-K, Chen M-L. Critical components in evaluating the performance of food waste composting plants. Sci Total Environ 2006;370:323-99.

Miller FC. Minimizing odor generation. In: Hoitink HAJ, Keener HM, editors. Science and Engineering of composting: design, environmental microbiological and utilization aspects. Wooster, OH: The OHIO State University; 1993. p. 219-41.

Perucci P, Corazzi E, Pardo Martinez M, Adani F, Carati C, Rubino FM, Colombi A, Calcaterra E, Benfenati E. Volatile organic compounds produced during the aerobic biological processing of municipal solid waste in a pilot plant. Chemosphere 2005;59:423-30.

Romain AC, Godefroid D, Nicolas J. Monitoring the exhaust air of a compost pile with an e nose and comparison with GC-MS data. Sens Actuators B 2005;106:317-24.

Said-Pullicino D, Gigliotti G. Oxidative biodegradation of dissolved organic matter during composting. Chemosphere 2007;68:1030-40.

Schlegelmilch M, Streese J, Biedermann W, Herold T, Stegmann R. Odour control at biowaste composting facilities. Waste Manage 2005;25:917-27.

Smet E, Van Langenhove H, De Bo I. The emission of volatile compounds during the aerobic and the combined anaerobic/ aerobic composting of biowaste. Atmos Environ 1999;33:1295-303.

Suler DJ, Finstein MS. Effect of temperature, aeration and moisture on $\mathrm{CO} 2$ formation in bench-scale, continuously thermophilic composting of solid waste. App Environ Microbiol 1977;33:345-50.

The U.S. Composting Council. Test methods for the examination of composting and compost. Bethesda, Maryland: The U.S. Composting Council; 1997. 